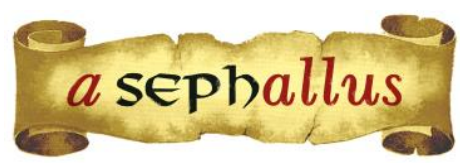

Revista aSEPHallus de Orientação Lacaniana

Núcleo Sephora de Pesquisa sobre o Moderno e o Contemporâneo

ISSN $1809-709 X$

\title{
Versões contraditórias no campo da ciência: politização e desinformação na prevenção à Covid- 19
}

\author{
Tania Coelho dos Santos \\ Orcid: https://orcid.org/0000-0002-5360-7864 \\ Pós-doutorado no Departamento de Psicanálise de Paris VIII (Paris, França) \\ Professor Associado, nível IV no Programa de Pós-graduação em \\ Teoria Psicanalítica/UFRJ (Rio de Janeiro, Brasil) \\ Pesquisadora do CNPQ nível $1 \mathrm{C}$ \\ Presidente do Instituto Sephora de Ensino e \\ Pesquisa de Orientação Lacaniana/ ISEPOL (Rio de Janeiro, Brasil) \\ Psicanalista Membro da École de La Cause Freudienne, \\ da Escola Brasileira de Psicanálise e da Associação Mundial de Psicanálise \\ Membro da Associação Universitária de Pesquisa \\ em Psicopatologia Fundamental (Rio de Janeiro, Brasil) \\ E-mail: taniacs@openlink.com.br
}

\begin{abstract}
Resumo: Para 80\% dos infectados a Covid-19, nome da infecção que o novo coronavírus provoca, não passa de uma virose assintomática, com sintomas leves ou moderados. Porém, $5 \%$ dos indivíduos infectados desenvolvem sintomas muito graves, cujo tratamento é bastante complexo e pode levá-los a óbito. Difundiuse na grande imprensa a ideia de que no tratamento desta doença, o conhecimento médico-científico consolidado, ao longo da experiência no tratamento de infecções respiratórias similares não serviria para nada. Desta forma, produziu-se entre os médicos assistentes uma enorme timidez ao explicar à imprensa que a utilização de métodos tradicionais de tratamento ainda era válida e não precisaria de complicados experimentos científicos para justificá-los. No público atingido pelas campanhas movidas pela imprensa observamos efeitos psicopatológicos de angústia intensa, insônia, falta de ar, fantasia de morte iminente e pânico.
\end{abstract}

Palavras-chave: Covid-19, Novo coronavírus, Métodos tradicionais de tratamento, Efeitos psicopatológicos.

\begin{abstract}
Versions contradictoires dans le domaine scientifique: politisation et désinformation das la prévention du Covid-19: Pour $80 \%$ des personnes infectées par Covid-19, le nom de l'infection que provoque le nouveau coronavirus, il ne s'agit que d'une infection virale asymptomatique avec des symptômes légers ou modérés. Cependant, $5 \%$ des personnes infectées développent des symptômes très graves, dont le traitement est assez complexe et peut les conduire à la mort. Il semble que dans le traitement de cette maladie, les connaissances médico-scientifiques consolidées, grâce à l'expérience acquise dans le traitement d'infections respiratoires similaires, ne sont d'aucune utilité. Ainsi, une énorme timidité s'est manifestée parmi les médecins traitants lorsqu'ils ont eté appelés a expliquer à la presse que l'utilisation des méthodes traditionnelles de traitement était toujours valable et qu'il n'était pas nécessaire de recourir à des expériences scientifiques compliquées pour les justifier. Dans le public touché par les campagnes menées par la presse, nous avons observé des effets psychopathologiques d'angoisse intense, d'insomnie, d'essoufflement, de fantasme de mort imminente et de panique.
\end{abstract}

Mots-clés: Covid-19, Nouveau coronavirus, Méthodes traditionnelles de traitement, Effets psychopathologiques

Contradictory versions in the field of science: politicisation and misinformation in the prevention of Covid-19: For $80 \%$ of those infected with Covid-19, the name of the infection that the new coronavirus causes, it is nothing more than an asymptomatic viral infection with mild or moderate symptoms. However, 
Revista aSEPHallus de Orientação Lacaniana

Núcleo Sephora de Pesquisa sobre o Moderno e o Contemporâneo

ISSN $1809-709$ X

$5 \%$ of infected individuals develop very severe symptoms, whose treatment is quite complex and can lead them to death. It appears that in the treatment of this disease, the consolidated medical-scientific knowledge, throughout the experience in the treatment of similar respiratory infections, is of no use. Thus, an enormous inhibition was produced among the attending physicians when explaining to the press that the use of traditional methods of treatment was still valid and would not need complicated scientific experiments to justify them. In the public affected by the campaigns moved by the press we observed psychopathological effects of intense anguish, insomnia, shortness of breath, fantasy of imminent death and panic.

Keywords: New coronavirus, Covid-19, Traditional methods of treatment, Psychopathological effects. 
Revista aSEPHallus de Orientação Lacaniana

Núcleo Sephora de Pesquisa sobre o Moderno e o Contemporâneo

ISSN $1809-709$ X

\section{Versões contraditórias no campo da ciência: politização e desinformação na prevenção à Covid-19}

Tania Coelho dos Santos

\section{Memórias da pandemia do novo coronavírus}

Estava a caminho de Paris na quinta feira, dia 19 de fevereiro de 2020. Na semana seguinte, a cidade do Rio de Janeiro seria tomada pela costumeira horda de turistas. Despreocupados, invadiriam as praias esbaldando-se sob o sol quente. Não demorariam a cair no samba em alguns dos nossos alegres blocos de carnaval. Entusiasmados, não tardariam a descobrir que não existe pecado do lado de baixo do equador. Nada parecia mais distante da preocupação das autoridades sanitárias que a possível chegada do novo coronavírus. Noutras partes do mundo, esse vírus já começava a tirar o sono das pessoas mais prudentes

Não pensei em comprar máscaras para usar no aeroporto ou no avião, mas mantive a distância física, um lenço sobre a boca e o nariz, além de redobrar os cuidados com higiene das mãos evitando levá-las aos olhos, nariz e boca. Usei luvas durante dez dias. Sim, eu estava tensa. Ao chegar troquei algumas ideias com Patrice, meu taxista francês nascido em Taiwan. Acostumado a me pegar e a me levar ao aeroporto, nunca perde a ocasião de me contar, orgulhoso, as novidades acerca de sua família e seu trabalho em Paris. Naquele dia estava exultante com sua nova Mercedes azul marinho toda forrada de branco por dentro. Tratei de sondar se ele estava preocupado com a eventual chegada do vírus à França. Mas ele estava alheio ao problema e mostrava-se alegre e otimista como de costume. Durante minha estadia, tomei cuidados adicionais. Arejava o quarto depois que a camareira fazia a limpeza e não saia à rua sem proteger o nariz e a boca. Passei a frequentar restaurantes somente quando estavam vazios, manter distância física no metrô e também durante a única visita ao Louvre.

Não foi nenhuma surpresa quando tomei conhecimento pelo Le Monde sobre o primeiro caso registrado, pois era iminente a chegada do vírus a Europa. Em 24 de fevereiro foi anunciado que não havia casos ativos no país. Em 25 de fevereiro, Dominique Varoteaux, professor de tecnologia na faculdade Jean-de-la-Fontaine em Crépy-en-Valois e vereador municipal em Vaumoise, morre de embolia pulmonar no hospital Salpêtrière em Paris. Esse homem de 60 anos, infectado com o vírus, se torna o primeiro cidadão francês a morrer de Covid-19 desde o início da epidemia global. Cinco novas pessoas com a doença foram diagnosticadas em 25 e 26 de fevereiro.

De volta ao Brasil no dia 29 de fevereiro, havia contraído uma gripe forte com muita tosse, bronquite e febre. Procurei meu médico para fazer um teste, mas nenhum laboratório podia oferecê-lo. Com base na minha medicina cabocla e ampla experiência em episódios de bronquite, decidi que não se tratava do corona. Só obtive a confirmação sorológica do IGG e IGA negativos 
Revista aSEPHallus de Orientação Lacaniana

Núcleo Sephora de Pesquisa sobre o Moderno e o Contemporâneo

ISSN 1809 - $709 \mathrm{X}$

no dia 8 de maio. Tive sorte. Muita gente não teve a mesma sorte e, uma vez infectado com o novo coronavírus, esperou tempo demais para receber o atendimento necessário. Muitos dos óbitos que ocorreram na rede privada no Rio de Janeiro aconteceram em consequência da demora em identificar a doença e providenciar o tratamento precocemente.

Embora só tenha deixado de receber meus analisandos no dia 23 de março, já havia incorporado todas as medidas obsessivas de prevenção ao contágio, que se tornariam os primeiros efeitos psicopatológicos da pandemia. Gestos tão simples como tocar o rosto, os olhos, o nariz ou a boca se tornaram perigosas ameaças, desencadeando uma permanente vigilância. Também uma ansiedade difusa, uma desconfiança de tudo e de todos, higienização obrigatória das mãos e de compras de farmácia e supermercado, configurava um novo sintoma obsessivo compulsivo como fortes tonalidades esquizo-paranoides. Muito pouco singulares, esses sintomas eram compartilhados com muitos outros indivíduos psicologicamente infectados pelo medo insano de contaminar-se.

\section{Do desconhecimento normal à desinformação ativa}

O novo coronavírus não provoca uma gripe comum. Para $80 \%$ dos infectados a Covid-19, nome da infecção que ele provoca, não passa de uma virose com sintomas leves ou apenas um pouco incômodos. O fenômeno que ninguém conseguiu explicar satisfatoriamente é: porque $5 \%$ dos indivíduos infectados desenvolvem sintomas muito graves, cujo tratamento é bastante complexo e não garante que poderá salvá-los da morte. Por causa deste detalhe, tudo que se difundiu na grande imprensa sobre o comportamento da doença parecia basear-se na suposição de que o conhecimento médico-científico consolidado, ao longo da experiência no tratamento de infecções respiratórias similares - as Síndromes Respiratórias Agudas Graves (SARGS) -, não serviria para nada no caso dessa nova infecção. Desta forma, produziu-se entre os médicos assistentes uma enorme timidez ao explicar à imprensa que a utilização de métodos tradicionais de tratamento ainda era válida e não precisaria de complicados experimentos científicos para justificálos. Reproduzo um pequeno trecho do artigo de um jornalista sensato, Eurípedes Alcântara, que traduziu muito bem a questão que os intimidava:

Médicos de hospitais privados no Brasil e nos Estados Unidos têm prescrito hidroxicloroquina para pessoas jovens com sintomas iniciais de Covid-19, sem problemas cardíacos ou outras comorbidades. Entendo que oficialmente se recusem a falar sobre isso com o objetivo de fugir do fogo do debate ideológico em torno do remédio. Mas é um fato comprovável. Conclusão: caso me infecte com o novo coronavírus quero que a decisão de tomar hidroxicloroquina seja tomada pelo médico encarregado do meu caso. (Alcântara, 2020, mai.) 
Revista aSEPHallus de Orientação Lacaniana

Núcleo Sephora de Pesquisa sobre o Moderno e o Contemporâneo

ISSN 1809 - $709 \mathrm{X}$

O que vou relatar parece uma anedota, mas, serve para deslocar o debate acerca da cientificidade da hidroxicloroquina para uma outra substância politicamente mais neutra. Cerca de três meses depois que a pandemia chegou ao Brasil, cientistas na Inglaterra descobriram que o emprego da boa e velha dexametasona (vulgarmente conhecida como Decadron) era muito eficiente para combater um sintoma, a pneumonia. Evidenciou-se, neste caso e em muitos outros, que houve uma supervalorização de estudos científicos baseados em metodologias tais como o duplo cego, para testar medicamentos cuja eficácia clínica estava consolidada há muito tempo apenas com base na experiência prática. Um enorme onda de desconfiança erigiu-se no debate público disseminado na imprensa contra certas práticas médicas tradicionais consolidadas pelo uso.

Assim, o maior problema que essa doença chamada Covid-19 nos trouxe foi a desorientação no exercício da prática médica tanto na saúde pública quanto na privada. Os efeitos psicopatológicos mais comuns sobre a opinião pública, dessa desorientação, foram a disseminação do pânico. Alguns indivíduos reagiram ao conflito de versões com uma indiferença defensiva aos arautos do perigo. A má qualidade da informação científica veiculada pela imprensa pode explicarse pelo fato de que entre os colegas cientistas e os médicos assistentes, faltou um mínimo de consenso. Alguns pesquisadores que considero altamente competentes e qualificados foram incapazes de transmitir de forma clara e ordenada seus conhecimentos sobre a doença, auxiliando a população a tomar decisões bem orientadas. Houve muita pressa em convencer a opinião pública das virtudes do isolamento e para isso os formadores de opinião não mediram esforços para pintar um quadro dantesco da infecção.

Disseminou-se amplamente a ideia de que o sistema imunológico dos indivíduos idosos, maiores de 60 anos, assim como daqueles que apresentam algum tipo de comorbidade (tal como doenças respiratórias prévias, hipertensão, obesidade, diabetes e doenças cardiovasculares em geral) seria incapaz de defender-se em caso de infecção. Era quase uma sentença de morte. Todos os idosos passaram a considerar-se altamente vulneráveis e responderam com uma angústia insuportável diante da ameaça de morte iminente. Trancaram-se em casa ou, paradoxalmente, negaram os perigos da doença lançando-se imprudentemente nas ruas. Em tratamento analítico, muitos deles deram testemunho do estado de pânico em que passaram a viver através de pesadelos, doenças psicossomáticas e outros sintomas de angústia. Muita gente passou a sofrer de insuficiência respiratória de origem psíquica, insônia, crises de choro e pesadelos diante da certeza absoluta de que a morte estava muito próxima. O tempo mostrou que as notícias que vieram de fora do país acerca da extrema vulnerabilidade dos idosos eram inexatas. Na prática, uma enorme quantidade deles tiveram apenas sintomas leves, ficaram assintomáticos ou chegaram a ser internados, mas se recuperaram. Os argumentos a favor da crença na fragilidade do sistema imunológico dos idosos respaldavam-se num paradoxo, de acordo com as informações que 
Revista aSEPHallus de Orientação Lacaniana

Núcleo Sephora de Pesquisa sobre o Moderno e o Contemporâneo

ISSN 1809 - $709 \mathrm{X}$

encontrei. Supostamente, por terem sido expostos a uma grande quantidade de outros vírus, não teriam defesas contra este novo vírus. As crianças, de acordo com este mesmo paradoxo, seriam imunes à nova doença porque tiveram baixa exposição a outras viroses.

Também não era verdadeira a ideia de que os portadores de comorbidades seriam, necessariamente, mais vulneráveis ao vírus. Isso só se mostrou um raciocínio válido quando o indivíduo desenvolveu a forma grave da doença. De fato, as pessoas que desenvolveram a forma grave da doença, quando apresentavam comorbidades, eram muito mais difíceis de tratar e de salvar da morte. Entretanto, ninguém foi capaz de apresentar uma boa explicação para o fato de alguns indivíduos, mesmo quando eram jovens e saudáveis, desenvolverem sintoma graves. Assim, a totalidade dos indivíduos, supostamente vulneráveis, foram expostos a uma propaganda maciça de informações inexatas e alardeadas com exagero, que geraram um clima ameaçador de proporções irresponsáveis. É inquestionável que a liberdade da imprensa informar é um valor irrelativizável numa sociedade democrática. Entretanto, muitos jornalistas entendem que sua missão é a de formar e não apenas informar a opinião pública. Suspeitamos que muitos indivíduos sentiram-se assediados pelo Ihes pareceu uma defesa exacerbada de uma política de isolamento social. Para alcançar a persuasão da opinião pública, pareceu justificável desenhar um quadro da doença mais ameaçador e mortífero do que a realidade.

Esse fenômeno demonstra que o problema das fake news é muito complexo. A propaganda de ideias inexatas pode ser desencadeada sem que, necessariamente, o agente da campanha (des) informadora tenha a intenção de mentir, iludir ou enganar. As conviç̧ões de jornalistas alinhados com uma determinada orientação política é suficiente para não deixar espaço para o contraditório, reduzindo o direito da população a informações com um mínimo de isenção. Para evidenciar essa percepção que trago do assunto destaco que no momento em que concluo esse artigo, o Brasil alcançou a marca de quase 100.000 mortos. É um número imenso e só podemos nos entristecer com isso e nos solidarizar com as famílias que perderam entes queridos. A imprensa, entretanto, alardeia que o Brasil é o segundo país do mundo em número de mortos, coisa altamente vexatória. Deixa na sombra que proporcionalmente ao tamanho relativo da população, o numero de mortos no Brasil é igual ao da França e menor que o da Itália ou da Inglaterra. Há muitas maneiras de manipular a opinião pública sem mentir. Uma delas é divulgar números absolutos e ocultar análises baseadas na proporção estatística. Qual é o interesse que alguns jornalistas manifestam em denegrir a reputação do Brasil? Atacar Jair Bolsonaro e sua opção política pela economia? É justo que este objetivo leve a denegrir o Brasil veiculando informações parciais e distorcidas?

A gravidade dos efeitos psicológicos da epidemia, do meu ponto de vista, se deveu menos ao seu ineditismo e muito mais à falta de transmissão adequada dos conhecimentos adquiridos ao longo da experiência de tratamentos bem sucedidos na China e na Europa. Por que tantos médicos 
Revista aSEPHallus de Orientação Lacaniana

Núcleo Sephora de Pesquisa sobre o Moderno e o Contemporâneo

ISSN 1809 - $709 \mathrm{X}$

não sabiam ou resistiram à ideia de que o tratamento precoce com anti-virais (como a azitromicina, a hidroxicloroquina, a ivermectina e outros medicamentos muito conhecidos) poderia inibir a proliferação do vírus nas fases iniciais da doença? Por descrédito em tratamentos precoces, os indivíduos foram orientados a permanecer em casa, não procurar os hospitais, a solicitar somente orientação ao seu médico pelo telefone ou orientar-se por aplicativos do ministério da saúde. Foi assim que muita gente desenvolveu um quadro de insuficiência respiratória grave e foi apanhado na armadilha perversa de uma doença que infecta o centro nervoso que permitiria ao doente perceber a falta de ar. Insensível à gravidade do seu estado, o doente não procura 0 hospital. A demora em receber o tratamento adequado levou muitos indivíduos, no início da pandemia, a desenvolver a forma mais grave da doença sem poder contar com o tratamento intensivo a tempo de estancar o progresso da infecção.

Em consequência da falta de informações mais confiáveis, desenvolveu-se no Brasil uma guerra de versões no campo da ciência. Médicos assistentes defensores do já mencionado tratamento precoce e do uso adequado de medicações tradicionais contrapunham-se aos epidemiologistas radicais convencidos de que era melhor prevenir do que tratar. A descrença em tratamentos eficazes os levou, inclusive, a uma campanha política em defesa do isolamento social que caiu no gosto da imprensa. A mensagem para o grande público era clara. Não há tratamento confiável. É preciso evitar o contágio a qualquer custo. O isolamento social, entretanto, não se mostrava praticável nas comunidades onde a densidade populacional é muito grande e as pessoas vivem aglomeradas em residências muito pequenas. O Ministério da Saúde, no início da pandemia, abraçou a causa do isolamento e da higiene das mãos com bastante entusiasmo e não se lembrou de advogar medidas alternativas tais como o uso de máscaras caseiras. Henrique Mandetta, num vigoroso esforço de divulgar as medidas tomadas pelo Ministério da Saúde e demonstrar o acompanhamento diário e cuidadoso do avanço da epidemia, reunia todos os dias um grande número de jornalistas para uma entrevista coletiva. Este showmício lhe valeu a suspeita de estar em campanha política para governador do Estado de Mato Grosso do Sul e transformou-se num poderoso combustível para a sua demissão. Infelizmente a atitude energicamente negacionista em relação a gravidade da doença manifestada pelo presidente da República levou a uma politização do tema da prevenção. O jornalista Demétrio Magnoli retrata bem essa situação:

A polarização política contaminou as discussões sobre a crise sanitária. O negacionismo bolsonarista provocou uma reação dogmática que domina a imprensa e a parcela mais esclarecida da opinião pública: Se Bolsonaro fala em abrir, exigimos fechar", No lugar do debate racional de custos e benefícios de cada restrição sanitária específica, as vozes indignadas com a criminosa negligência do governo federal refugiam-se no clamor 
Revista aSEPHallus de Orientação Lacaniana

Núcleo Sephora de Pesquisa sobre o Moderno e o Contemporâneo

ISSN 1809 - $709 \mathrm{X}$

genérico por lockdowns. Nesse passo, o pensamento supostamente progressista limita-se a reproduzir a cartilha bolsonarista - apenas virando-a do avesso. (Magnoli, 2020)

Para acrescentar um pouco mais ainda de insensatez ao debate, os presidentes Jair Bolsonaro e Donald Trump tornaram-se ardorosos defensores do uso precoce da hidroxicloroquina. Acredito que se tratava de uma estratégia para incentivar as pessoas a não se isolarem em casa e deixarem de sair para trabalhar. A defesa do tratamento precoce foi interpretada por grande parte da imprensa (Pasternak, N. et alli, 2020) como a defesa do uso preventivo do medicamento. Depois disso a discussão sobre esse medicamento foi completamente politizada. À direita, os "corajosos" defensores do tratamento precoce com hidroxicloroquina (ou similares como Ivermectina e Nitazoxanida) e anti-virais como a Azitromicina. À esquerda, os "conscientes" defensores da prudência extrema que somente um isolamento social rígido e prolongado poderia assegurar. A ciência tornou-se o palco decepcionante de controvérsias suspeitas de coloração política, contribuindo para aumentar a desinformação e o acirramento dos ânimos na imprensa. 0 comportamento de grande parte dos jornalistas, por esta razão, não foi elogiável. Faltou isenção e veio a demonstrar que não suportam o contraditório. O espírito das novelas de televisão dominou um debate entre bandidos e mocinhos. Gay Talese, conhecido jornalista e escritor americano, observou que a mídia contemporânea se comporta como as redes sociais. E, nas redes sociais, predominam as mentes preguiçosas. Ele denuncia as manobras mal-intencionadas de jornalistas que introduzem "pegadinhas" nas perguntas para induzir o entrevistado a fazer declarações prejudiciais à sua integridade e reputação. E vai mais longe ainda declarando que: "Todo mundo tem opiniões sobre moralidade e justiça. Isso não quer dizer que se deva impor uma visão unilateral a quem pensa diferente e esteja contribuindo em um espaço de opinião". (Talese, 2020, agosto)

No centro dessa desinformação habitava o profundo desconhecimento de que a doença passa por três fases. Somente em dezessete de abril tive acesso a uma reunião por Zoom organizada pelo pesquisador Sergio Margulies (youtube) entre o hematologista e oncologista Daniel Tabak e o infectologista e pesquisador da UFRJ Mauro Schechter. Fiquei sabendo que o início da doença é apenas uma virose comum mas que, se ela evolui, sobrevém uma insuficiência respiratória grave em consequência de um complexo processo inflamatório dos pulmões. Essa insuficiência muitas vezes não é percebida como tal. A infecção atinge centros neurológicos mais periféricos responsáveis pela identificação da falta de ar. Com isso o sujeito pode negligenciar a gravidade do seu estado. Acrescente-se que a doença pode ser trombofílica e provocar um quadro cardio-vascular perigoso. E, finalmente, ela pode levar a uma grave descompensação imunológica, uma tempestade de citocinas que exige manobras paradoxais de imunodepressão. Em lugar deste conhecimento precioso e realista, assistimos na imprensa as aventuras do Ministério da Saúde na 
Revista aSEPHallus de Orientação Lacaniana

Núcleo Sephora de Pesquisa sobre o Moderno e o Contemporâneo

ISSN 1809 - 709 X

luta desesperada para comprar ventiladores mecânicos. Recursos técnicos que foram supervalorizados como se todo o tratamento possível se reduzisse a isso.

O Ministro da Saúde teve dificuldade também em lidar com as diferenças entre o sistema público de saúde e o privado. No esforço de evitar uma superlotação das emergências dos hospitais públicos, recomendou amplamente a todas as pessoas doentes permanecerem em casa. O diagnóstico e a intervenção precoce foram desestimulados generalizadamente. No Rio de Janeiro, a epidemia chegou primeiramente aos hospitais privados da Zona Sul e da Barra da Tijuca. Encorajar os pacientes que têm plano de saúde a não procurar os hospitais privados não foi a melhor conduta. Na rede pública, a epidemia demorou um pouco mais a chegar, o que ajudou bastante a não sobrecarregar demais a rede antes que ela fosse melhor aparelhada para receber os enfermos. Não foi a recomendação generalizada de não procurar os hospitais públicos, entretanto, o que salvou alguns deles do tão anunciado caos. Foi um fato inusitado que observamos nas comunidades próximas às regiões mais abastadas da cidade. Voltaremos a esse ponto mais abaixo.

\section{Do melancólico despreparo à resposta eficiente dos hospitais privados}

No dia 21 de março reuni presencialmente pela última vez as equipes de psicólogos da Rede D'Or e da United Health Group (Rede Amil) que supervisiono semanalmente. Passamos a nos reunir virtualmente em seguida. Na ocasião, recomendei que procurassem as direções dos hospitais para sugerir a compra de máscaras caseiras. Não havia equipamento de proteção individual suficiente e seu destino era reservado aos profissionais de saúde que estavam em contato direto com pacientes infectados. Sugeri também que nos organizássemos para trabalhar virtualmente e começamos a ampliar o programa de assistência aos colaboradores para receber todos aqueles que apresentassem sintomas de ansiedade relacionados ao medo do contágio pelo novo coronavírus.

Estas redes privadas de saúde surpreenderam muito positivamente. No início de março, todos aqueles que trabalham em hospitais esperavam o apocalipse. Não havia equipamento de proteção individual suficiente nem leitos de CTI, não havia protocolo de tratamento dessa doença ainda desconhecida, não havia intensivistas treinados, nem médicos em número suficiente para entubar os pacientes, muito menos ainda ventiladores mecânicos. Em pouco tempo mesmo, numa velocidade impressionantemente rápida, novos CTIs foram abertos, equipamentos especializados adquiridos, médicos contratados, equipes treinadas para a assistência e para a prevenção ao contágio. E os pacientes graves chegaram aos hospitais. Esperava-se que profissionais de saúde seriam infectados rapidamente ou desenvolveriam quadros psicológicos incapacitantes e tudo isso nos levaria ao caos. 
Revista aSEPHallus de Orientação Lacaniana

Núcleo Sephora de Pesquisa sobre o Moderno e o Contemporâneo

ISSN 1809 - $709 \mathrm{X}$

Nada disso aconteceu. A resposta das maiores redes hospitalares privadas do Rio de Janeiro se mostrou à altura do desafio. A quantidade de pacientes internados e que precisaram de CTI foi enorme mas nunca se chegou a anunciada superlotação. A fantasia macabra que assombrava corações e mentes era a de que os profissionais de saúde seriam obrigados a escolher entre quem receberia um respirador e quem seria entregue a própria sorte. A letalidade foi relativamente baixa e atingiu sobretudo pacientes que estavam em tratamento de outras doenças, câncer em particular, ou idosos com algumas comorbidades mais graves. O aspecto mais surpreendente foi a grande quantidade de indivíduos que, independentemente de serem bem jovens, desenvolveram a forma grave da doença por causa da obesidade. $E$ ainda tem gente que não acredita que obesidade é doença. Gente que pensa que se trata do preconceito politicamente incorreto de gordofobia. Um outro aspecto marcante foi o número de pacientes do sexo masculino que desenvolveram a forma grave da doença. É possível que isso venha a confirmar uma velha constatação, os homens cuidam bem menos da saúde do que as mulheres. Ou, quem sabe, as diferenças hormonais expliquem o fenômeno.

Enquanto supervisora das equipes de psicólogos que trabalham na assistência de alguns dos maiores hospitais privados da Zona Sul e da Barra, fui testemunha do esforço incansável e do apoio incondicional das direções ao nosso trabalho. Em pouco tempo o atendimento virtual aos pacientes com Covid-19 e às suas famílias expandiu-se e mostrou-se muito responsável e eficiente. O que mais chamou minha atenção, entretanto, foi o trabalho com os colaboradores. Se no início da pandemia muitos deles pareciam fragilizados e com muito medo de contaminar-se ou às suas famílias, a rápida e farta distribuição de equipamentos de proteção individual modificou este quadro. Em lugar da crise de ansiedade, pânico e do êxodo dos profissionais, pudemos testemunhar o elevado engajamento que demonstraram no enfrentamento dos múltiplos desafios.

Através de entrevistas com coordenadores médicos de CTIs e de emergências, bem como com a chefia da enfermagem (Coelho dos Santos, T. et alli, 2020) pudemos recolher as memórias do imenso esforço de adaptação à uma rotina que envolvia desde a prevenção ao contágio até a dedicação exaustiva a inúmeros pacientes que exigiam cuidados muito especializados e altamente individualizados. É notável a substituição de um ambiente melancólico de apreensão e despreparo entre os profissionais médicos, enfermeiros e técnicos de enfermagem por um espírito de enfrentamento e elevada abnegação. Em todas as entrevistas efetuadas com profissionais que estiveram na linha de frente pudemos verificar a importância da liderança exercida pela direção dos hospitais da rede privada.

Não acompanhei diretamente os esforços da rede pública no tratamento aos pacientes. Tive notícias somente através de algumas experiências isoladas que me foram trazidas por analisandos meus que são médicos e atuam em hospitais públicos. Em particular, me chamou a atenção o que me foi relatado por um analisando sobre o Hospital de campanha da Gávea. Os 
Revista aSEPHallus de Orientação Lacaniana

Núcleo Sephora de Pesquisa sobre o Moderno e o Contemporâneo

ISSN 1809 - $709 \mathrm{X}$

pacientes para lá encaminhados vinham de longe e, ao contrário do que se esperava, não vieram das comunidades hiperpopulosas da Zona Sul, São Conrado e Barra da Tijuca. Além disso, ressalto a coragem, a dedicação e o compromisso que esses médicos demonstraram. Em particular, destaco a extrema privação de confortos essenciais que tiveram que enfrentar tais como: alimentar-se quando se tem fome ou urinar quando se tem necessidade. Paramentar-se e desparamentar-se é uma tarefa árdua e os equipamentos são racionados. O plantão em CTIs com enfermos da Covid-19, nos chamados covidários, requer que o plantonista suspenda por seis horas consecutivas essas necessidades essenciais. O que para as mulheres é especialmente penoso, além de ser propício ao desenvolvimento de infecções urinárias, como me relatou uma analisanda que trabalhou no Gaffrée e Guinle.

\section{Quando cair nas comunidades vai ser um caos!}

Esta frase circulou de boca em boca no Rio de Janeiro e traduzia a certeza de que o apocalipse estava para chegar. Sabíamos que a estratégia de combate à epidemia baseada no isolamento social era inadequada às comunidades do Rio de Janeiro. Entretanto, um fato bastante insólito e que merece um estudo aprofundado foi o seguinte: o fim do mundo não chegou. Porque a doença que levou aos hospitais uma grande quantidade de pessoas dos grupos sociais mais abastados, não trouxe uma catástrofe às comunidades do Rio de Janeiro. O numero de indivíduos que precisaram ser hospitalizados em estado grave na Rocinha, Vidigal, Rio das Pedras, Tijuquinha, Muzema, Maré, não foi calamitoso. Ao contrário, é surpreendente que, não podendo seguir a orientação do Ministério da Saúde para manter-se em isolamento, nem por isso a letalidade nestes grupos foi mais expressiva.

Uma pesquisa inédita do Instituto de Pesquisa Econômica Aplicada (Ipea), não parece corroborar nossa percepção intuitiva do fenômeno, pois mostrou que 79,6\% dos 6735 óbitos registrados na capital até o dia 13 de junho ocorreram nas áreas mais pobres da cidade, longe da Zona Sul, Barra, Grande Tijuca onde o IDS é mais alto. Se analisarmos os dados com mais atenção, entretanto, talvez estejamos no caminho certo. A Rocinha, por exemplo, foi incluída na zona 1, a de IDS mais baixo, juntamente com o Complexo do Alemão, Camorim, Deodoro, Acari, Parada de Lucas e Jacarepaguá. Observou-se que o índice de letalidade em todas as faixas de idade foi muito mais alto do que na zona 5 que compreende a Zona Sul, a Barra, Tijuca, Meier e Jardim Guanabara. A percepção intuitiva de que não houve um caos nas favelas próximas à Zona Sul e à Barra não pode, entretanto, ser corretamente aferida, pois os dados acerca destas regiões estão diluídos entre informações relativas às outras regiões mais pobres da capital. Se a Rocinha e o Vidigal fazem parte da zona 1 (a mais pobre da cidade e de menor IDS) por que o Hospital de campanha da Gávea, inaugurado no dia 23 de abril, não recebeu um número enorme de pacientes desta região? Para onde teriam sido encaminhados? Por que os moradores dessa região não 
Revista aSEPHallus de Orientação Lacaniana

Núcleo Sephora de Pesquisa sobre o Moderno e o Contemporâneo

ISSN 1809 - $709 \mathrm{X}$

relatam uma incidência significativa de óbitos? Somente uma explicação me ocorre para tamanha distância entre a realidade que observei no meu entrono e os dados do IPEA: a distribuição da letalidade na zona 1 (a mais pobre) não foi uniforme. Regiões com IDS idêntico podem não ter tido o mesmo índice de letalidade. Questão que não interessou pesquisar. Ela não é politicamente correta. A ciência infelizmente nem sempre leva em conta a contingência. Talvez, as comunidades mais próximas das regiões mais abastadas da cidade não tenham sofrido o mesmo impacto que outras, igualmente pobres, mas situadas em outras localidades. Talvez o apoio solidário dos moradores do entorno dessas comunidades tenha contribuído muito para reduzir significativamente o impacto da epidemia.

\section{O segredo da resposta imunológica desigual entre os seres humanos}

O debate sobre a vulnerabilidade ao novo coronavírus trouxe à luz alguns enigmas imunológicos que estão longe de terem sido decifrados. Alguns pesquisadores debatem a importância da imunidade cruzada. A vacinação contra a tuberculose, a velha BCG, seria uma das respostas à pergunta que não quer calar: por que tanta gente não pega a doença? Não há evidências definitivas de que a vacina Bacille Calmette-Guérin (BCG) proteja as pessoas contra a infecção pelo novo vírus. Dois ensaios clínicos que abordam essa questão estão em andamento e a OMS avaliará as evidências definitivas quando disponíveis. Entretanto, existem evidências experimentais de estudos em animais e humanos de que a vacina BCG tem efeitos inespecíficos mais amplos no sistema imunológico cuja relevância não foi ainda bem caracterizada. Porém, a revisão dessas pesquisas produziu dois protocolos registrados para ensaios clínicos com o objetivo de estudar os efeitos da vacinação BCG em profissionais de saúde diretamente envolvidos no atendimento a pacientes com Covid-19. Em 11 de abril de 2020, a OMS atualizou sua revisão de evidências em andamento dos principais bancos de dados científicos e repositórios de ensaios clínicos, usando termos de pesquisa em inglês, francês e chinês para Covid-19, coronavírus, SARSCoV-2 e BCG. A revisão produziu três pré-impressões (manuscritos publicados on-line antes da revisão por pares), nos quais os autores compararam a incidência de casos de Covid-19 em países onde a vacina BCG é usada com países onde não é usada e observaram que os países que usavam rotineiramente a vacina em neonatos tinha menos casos relatados de Covid-19 até aquele momento. Embora tais estudos sejam propensos a um viés significativo de muitos fatores de confusão, incluindo diferenças na demografia nacional e na carga de doenças, taxas de teste para infecções pelo vírus e o estágio da pandemia em cada país, há evidências preliminares a favor dos efeitos da BCG.

Outros pesquisadores (Pereira, R.C., Saúde/Abril, 2020) sugeriram que o segredo da imunidade reside nas altas taxas de vitamina $D$, um hormônio muito potente. Para produzi-lo, o organismo exposto ao sol forte transforma nele o ergosterol disponível no corpo. O ergosterol é 
Revista aSEPHallus de Orientação Lacaniana

Núcleo Sephora de Pesquisa sobre o Moderno e o Contemporâneo ISSN $1809-709 \mathrm{X}$

um esterol que é precursor da Vitamina $D_{2}$. (Wikipédia) É transformado em viosterol por ação da luz ultravioleta e que depois é convertido em ergocalciferol, que é uma forma de vitamina D. A prevenção à doença num país solar como o Brasil poderia ter contado com uma ampla campanha para reforçar a vitamina $D$. Sabemos que muitos médicos assistentes aconselharam seus pacientes particulares a fortalecer a imunidade tomando suplementos vitamínicos. A vitamina $D$ é muito importante para o corpo humano. Além de suas funções mais conhecidas relacionadas à saúde dos ossos, é responsável também por outras atividades, trabalhando como reguladora do crescimento, sistema imunológico, cardiovascular, músculos, metabolismo e insulina. Mas, quando descoberta, acreditava-se que ela só poderia ser adquirida por meio de alimentos. Foi na década de 70 que os cientistas descobriram que a vitamina era um hormônio e não uma vitamina, mas sua nomenclatura já estava consolidada e assim permaneceu. Pode ser encontrada ainda em alguns poucos alimentos, como peixes gordurosos, óleo de fígado de bacalhau e cogumelos secos. Leite, ovos e fígado bovino também têm a vitamina, mas em menor quantidade. Estes alimentos não são típicos da dieta da população de baixa renda. Além disso, para suprir a necessidade diária de vitamina $D$, é necessário o consumo de grandes quantidades desses alimentos. Por outro lado, a principal fonte no nosso organismo vem da sua síntese na pele, por ação da luz solar. A vitamina D é lipossolúvel, ou seja, para ser absorvida no intestino, precisa da presença de gorduras, quando adquirida por meio de alimentos. A principal fonte de vitamina $D$ é a nossa pele, o ideal é tomarmos sol sem filtro solar por pelo menos 20 minutos por dia. As células que fazem parte do sistema imunológico, como os linfócitos, têm receptores para a vitamina $D$, que atua no fortalecimento do sistema de defesa, auxiliando na prevenção de doenças. Considerando que a população de baixa renda não costuma se alimentar bem, a exposição maciça à luz solar justificaria o alto grau de imunidade que poderia explicar a baixa letalidade nas comunidades que mencionamos acima?

Não menos importante é a imunidade intracelular. Não são somente os anticorpos que nos protegem do vírus. Linfócitos T ou células T são células do sistema imunológico e também um grupo de glóbulos brancos (leucócitos) responsáveis pela defesa do organismo contra agentes desconhecidos. (Wikipedia) Seu papel principal é como imunidade específica, imunidade celular, induzindo a Apoptose (autodestruição) de células invadidas por vírus, bactérias intracelulares, danificadas ou cancerígenas. Diferenciam-se de acordo com sua função em: citotóxicas (CD8), auxiliares (CD4), natural killer (NKT), memória (CD45), reguladoras (FOXP3) ou gama-delta ( $ү \delta)$. Amadurecem no timo, por isso se chamam linfócitos.

Finalmente, há toda uma discussão acerca da imunidade genética. Por que algumas poucas pessoas desenvolvem formas graves da Covid-19, enquanto muitas outras permanecem assintomáticas? A pesquisadora Mayana Zatz (Mariz, F. Jornal da USP, 2020), diretora do Centro de Pesquisas do Genoma Humano e Células-Tronco (CEGH-CEL) da USP, está participando de um 
Revista aSEPHallus de Orientação Lacaniana

Núcleo Sephora de Pesquisa sobre o Moderno e o Contemporâneo

ISSN 1809 - $709 \mathrm{X}$

grupo de pesquisa internacional que procura entender como os genes influenciam a doença. Uma das características da infecção pelo novo coronavírus é a variabilidade de sintomas em pessoas infectadas. Ela verificou que a maioria das pessoas desenvolve sintomas leves ou permanece assintomática mas, cerca de $1 \%$ das pessoas com sintomas podem ter formas graves e letais. Essa diferença na resposta à infecção pelo novo coronavírus depende do nosso genoma. Por essa razão, a geneticista esclarece que os cientistas envolvidos no estudo, em parceria com o professor Paulo Saldiva, da Faculdade de Medicina (FM) da USP, querem identificar as variantes genéticas de risco e as variantes protetoras. Observou-se que há superidosos que expostos ao vírus não desenvolveram sintomas ou conseguiram curar-se da infecção. Há indivíduos jovens, geralmente do sexo masculino, que desenvolveram a forma grave da doença. E é muito provável que a principal razão da vulnerabilidade ao vírus dependa essencialmente do genoma de cada um. Conhecer quais são os genomas de risco e quais os que envolvem genes protetores é de longe a medida mais eficaz para estabelecer uma estratégia de prevenção da doença e também de vacinação.

Um grande consórcio europeu de pesquisa (Heise, 2020) já analisou o genoma de milhares de pacientes e sugeriu que parte da resistência pode ser explicada pelos genes dos grupos sanguíneos $A B O$. Pessoas com sangue tipo $A$ seriam mais vulneráveis e as com tipo $O$ seriam mais resistentes. As demais, ( $B$ e $A B$ ) ficariam no meio. Muita coisa ainda está por ser esclarecida e poderá explicar, talvez, porque o apocalipse não chegou.

\section{Desinformação, politização e psicopatologia: tem vacina contra isso?}

Para concluir, obtive grande parte dessas informações em pesquisas efetuadas na internet e que foram conduzidas apenas pela minha santa curiosidade. Na grande imprensa uma pequena parte destas informações chegou tarde, bastante insuficiente e mal apresentada. Em lugar de informação objetiva, bem fundamentada, clara e amplamente explicada, encontrei uma enorme quantidade de manifestações e conselhos de epidemiologistas convencidos de que entendem de tudo. Nada é mais distante do espírito científico do que a certeza absoluta. Nada está mais próximo do desejo de sugestionar, influenciar, dominar as mentes preguiçosas do que esses estados psicológicos de elevada conviç̧ão. Nada é mais propenso a disseminar o pior de todos efeitos psicopatológicos, a paranoia, do que o gosto de tantos cientistas pela certeza. Contribuem ativamente para a polarização política exagerada que domina todos os debates na atualidade. Exacerbam o sintoma histérico dominante que consiste em rejeitar o que é complexo e acreditar que para tudo existe uma solução simples. Exacerbam a tendência infantil, reinante em nossa época, de buscar um grande Outro mau (Miller, 2010) para culparmos por aquilo que não podemos controlar, evitar ou prevenir. Pode ser o meu vizinho que não usa máscara. Pode ser o idoso que rejeita o isolamento social. Ou o jovem que se aglomera com outros jovens no barzinho. 
Revista aSEPHallus de Orientação Lacaniana

Núcleo Sephora de Pesquisa sobre o Moderno e o Contemporâneo

ISSN 1809 - $709 \mathrm{X}$

Logo mais serão cancelados todos aqueles que se recusarão a tomar a vacina. É o que anuncia antecipadamente o editor chefe da Science, Holden Thorp (Eller, 2020), pois acredita que existe uma correlação entre a defesa da hidroxicloroquina e o movimento antivacina. Essa abordagem da posição dos indivíduos que cometeram o crime anticientífico de acreditar em tratamento precoce com antivirais serve para demonstrar o grau de polarização antidemocrática. Afinal, o movimento antivacina cresce entre indivíduos progressistas, politicamente corretos e de esquerda. Nada a ver com os correligionários de Bolsonaro ou Trump. A nossa ideia de democracia, em tempos de unilateralidade dos discursos progressistas e politicamente corretos, tornou-se inimiga das liberdades individuais. O patrulhamento da liberdade de opinião viola a liberdade de expressão. Estamos vivendo num mundo perigoso. $O$ medo de ter a sua reputação difamada tem levado muitas pessoas a se calarem. O resultado dessa cultura do cancelamento são as surpresas eleitorais que as maiorias silenciadas podem preparar para a inteligentsia progressista, globalizada e convencida de que sua opinião é a única opinião possível, a única que é politicamente correta, moralmente justa e religiosamente santificada.

\section{Referências bibliográficas:}

Alcântara, E. (2020, mai.). O médico decide O Globo. Medscape. Recuperado de https://oglobo.globo.com/opiniao/o-medico-decide-24441685

Altino, L. (2020, ago.). Menos dinheiro e mais dor Rio. $O$ Globo. Recuperado de https://oglobo.globo.com/rio/conheca-os-bairros-do-rio-com-as-maiores-taxas-demortalidade-por-casos-da-covid-19-24562333

Duqueroy, V. (2020, abr.). França publica mais dados sobre hidroxicloroquina e surgem mais dúvidas, Medscape. Recuperado de https://portugues.medscape.com/verartigo/6504711.

Eller, J. (2020, ago.) Entrevista com Holden Thorp. $O$ Globo Recuperado de https://oglobo.globo.com/sociedade/coronavirus/temo-que-as-pessoas-deixem-de-sevacinar-diz-editor-chefe-da-revista-science-1-24562178

Frellick, M. (2020, jun.) Hidroxicloroquina não previne a Covid-19 em um estudo randomizado. Medscape. Recuperado de https://portugues.medscape.com/verartigo/6504912.

Frellick, M. (2020, abr.) Mais um estudo confuso sobre hidroxicloroquina. Medscape. Recuperado de https://portugues.medscape.com/verartigo/6504753.

Grünewald, S. T. (2020, jul.) Pesquisa brasileira destaca ausência de benefício com hidroxicloroquina na covid-19. Medscape. Recuperado de https://portugues.medscape.com/verartigo/6505122. 
Revista aSEPHallus de Orientação Lacaniana

Núcleo Sephora de Pesquisa sobre o Moderno e o Contemporâneo ISSN 1809 - $709 \mathrm{X}$

Heise, G. (2020, jun.). Tipo sanguíneo pode influenciar evolução da covid-19. Recuperado de https://www.dw.com/pt-br/tipo-sangu\%C3\%ADneo-pode-influenciarevolu\%C3\%A7\%C3\%A3o-da-covid-19-diz-estudo/a-53874013

Kirkner, R.M. (2020, jun.). Covid-19: Distanciamento físico funciona e máscara N95 é a melhor, diz análise. Medscape. Recuperado de https://portugues.medscape.com/verartigo/6504913 Linfócito $\mathrm{T}$. Recuperado de https://pt.wikipedia.org/wiki/Linf\%C3\%B3cito_T\#: :text=Linf\%C3\%B3citos\%20T\%20ou \%20c\%C3\%A9lulas\%20T,contra\%20agentes\%20desconhecidos\%20(ant\%C3\%ADgenos).

Magnoli, D. (2020, ago.). O único consenso nacional. $O$ Globo. Recuperado de https://oglobo.globo.com/opiniao/o-unico-consenso-nacional-24575452

Tabak, D., Schechter, M. (2020, abr.). Recuperado de https://www.youtube.com/watch?v=DiAASIbyHmQ

Zatz, M. (2020, jun.). Pesquisa quer identificar genes responsáveis por forma grave da covid-19. Medscape. Recuperado de https://jornal.usp.br/radio-usp/passaporte-da-imunidadecontra-covid-19-ainda-gera-polemica-2/

McCall, B. (2020, mai.). Covid-19: Será a reposição de vitamina D uma solução simples e ao nosso alcance? Medscape. https://portugues.medscape.com/verartigo/6504877.

Medscape, E. (2020, jun.). Dexametasona reduz mortes em pacientes com covid-19 grave. Medscape. Recuperado de https://portugues.medscape.com/verartigo/6504944.

Miller, J.A. (2010.). L'Autre Mechant six cas cliniques commentés, Collection La Bibliothèque Lacanienne 4. Paris : Navarin.

Miranda, G. (2020, jun.). Isolamento horizontal x isolamento vertical: quais são as evidências? Medscape. Recuperado de https://portugues.medscape.com/verartigo/6504970.

Otto, M. A. (2020, mai.). Apresentações incomuns da Covid-19: 'Nossa ignorância é profunda'. Medscape. Recuperado de https://portugues.medscape.com/verartigo/6504822.

Pasternak, N., Schechter, M., Tabak, D. (2020, jul.). O holocausto e a cloroquina. Medscape. Recuperado de https://oglobo.globo.com/opiniao/o-holocausto-a-cloroquina-24532831.

Dias, B.C. (2020, mai.). Ineficácia da cloroquina contra a Covid-19 é confirmada em revisão de 70 referências. Recuperado de https://www.abrasco.org.br/site/noticias/especialcoronavirus/ineficacia-cloroquina-covid19-cientistas-anm/48463/

Pereira, R. C. (2020, mai.). Saúde Abril. A vitamina da controvérsia. Medscape. Recuperado de https://saude.abril.com.br/alimentacao/a-vitamina-da-controversia/

Salamon, M. (2020, jun.). Obesidade agrava Covid-19 em pacientes jovens? Medscape. Recuperado de: https://portugues.medscape.com/verartigo/6504903.

Tabakman, R. (2020, jun.). Higiene e limpeza na pandemia: A linha tênue entre precaução e obsessão. Medscape. Recuperado de https://portugues.medscape.com/verartigo/6504902. 
Revista aSEPHallus de Orientação Lacaniana

Núcleo Sephora de Pesquisa sobre o Moderno e o Contemporâneo

ISSN 1809 - $709 \mathrm{X}$

Talese, G. (2020, ago.). Sou absolutista da liberdade de expressão. O Globo. Recuperado de https://oglobo.globo.com/cultura/gay-talese-comenta-demissoes-no-new-york-timescultura-do-cancelamento-24562679

Tarantino, M. (2002, jun.). Maioria dos médicos aprova isolamento; APM vê perigo em flexibilizar agora, Recuperado de: https://portugues.medscape.com/verartigo/6504900

Vitamina D. Recuperado de https://pt.wikipedia.org/wiki/Vitamina_D

Citação/Citation: Coelho dos Santos, T. (nov. 2019 a abr. 2020). Versões contraditórias no campo da ciência: politização e desinformação na prevenção à Covid-19. Revista aSEPHallus de Orientação Lacaniana, 15(29), 6-22. Disponível em www.isepol.com/asephallus. Doi: 10.17852/1809709x.2020v15n29p06-22

Editor do artigo: Tania Coelho dos Santos.

Recebido/Received: 10/03/2019 / 03/10/2019.

Aceito/Accepted: 10/20/2019 / 20/10/2019.

Copyright: ( 2019 Associação Núcleo Sephora de Pesquisa sobre o moderno e o contemporâneo. Este é um artigo de livre acesso, que permite uso irrestrito, distribuição e reprodução em qualquer meio, desde que $o$ autor $e$ a fonte sejam citados/This is an open-access article, which permites unrestricted use, distribution, and reproduction in any medium, provided the author and source are credited. 